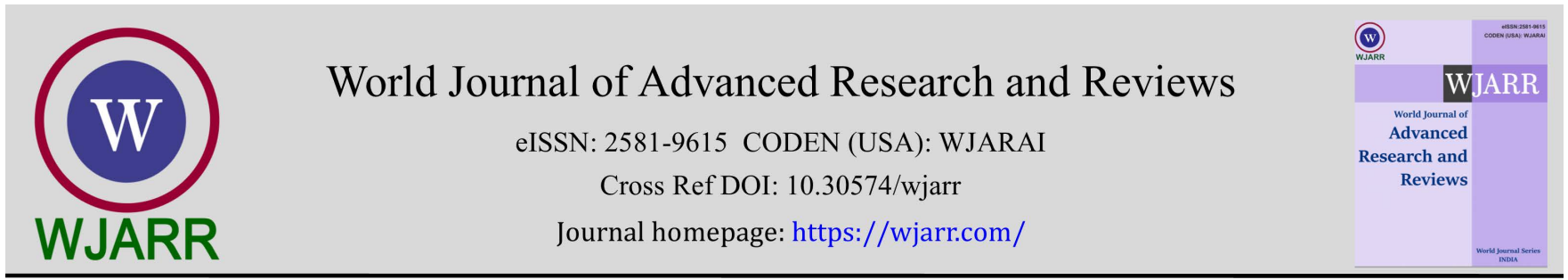

(REVIEW ARTICLE)

\title{
Ethnobotanics used as an external application to manage wounds in Sri Lankan traditional medicine; A scientific validation of Ola leaf manuscript evidences
}

\author{
Dinusha Balasooriya ${ }^{1}$, Shyamalie Wijesinghe ${ }^{1}$, Inoka Uluwaduge ${ }^{2}$ and Priyani Peiris ${ }^{3, *}$ \\ ${ }_{1}$ Department of Ayurveda Basic Principles, Gampaha Wickramarachchi Ayurveda Institute, University of Kelaniya, Sri \\ Lanka. \\ 2 Department of Basic Sciences, Faculty of Allied Health Sciences, University of Sri Jayewardenepura, Nugegoda, Sri Lanka. \\ ${ }^{3}$ Department of Shalya - Shalakya, Faculty of Indigenous Medicine, Gampaha Wickramarachchi University of Indigenous \\ Medicine, Sri Lanka.
}

World Journal of Advanced Research and Reviews, 2021, 12(01), 487-497

Publication history: Received on 15 September 2021; revised on 25 October 2021; accepted on 27 October 2021

Article DOI: https://doi.org/10.30574/wjarr.2021.12.1.0500

\begin{abstract}
Indigenous medicine is a unique entity of a medical system which has been proven as an effective and is in practice from ancient times in Sri Lanka. In this system, use of medicinal plants in different ailments are driven by popular knowledge through traditional healers. However, these claimed activities are neither scientifically proven nor refuted. This evidence-based study is focused on the scientific validation of commonly used herbs included in external applications to treat wounds in indigenous medicine. The data were gathered referring ancient Ola leaf manuscripts based on different herbal applications used for the treatment of wounds and analysed to reveal the plants which were mostly used in those different applications. The selected plant species were evaluated in terms of the current state -of-the-art for their pharmacology and effectiveness in wound healing.

Many external applications are used in treating wounds in different dosage forms such as oils, fresh juices, mellum, bolus fermentation, powders and fumigation. Pongamia pinnata and Vernonia zeylanica were found in highest number of remedies followed by Curcuma longa, Jasminum sambac, Azadirachta indica, Glycyrrhiza glabra and Desmodium triflorum. Current evidences suggest that the majority of the plants used were studied for their wound healing potential by in vivo studies as the current maximum level of scientific evidences available. Vernonia zeylanica is the least studied plant in the literature. Perhaps the endemicity of this plant to Sri Lanka could be the major reason for the scarcity of literature.
\end{abstract}

This is the first study systemically assessing of evidences from modern literature to support Ola leaf evidences on wound healing activity mentioned in traditional indigenous medical system of Sri Lanka.

Keywords: Indigenous medicine; Wound; External herbal applications; Pongamia pinnata

\section{Introduction}

Throughout the history man has had to contend with dermal wounds. Skin wounds affect the quality of the life of patients and considered as a major cause for physical disability [1]. Wound healing is a complex process and it includes coordination between diverse immunological and pathological processes. The healing process of an acute or chronic wound involves the scab formation, initial inflammation, and deposition of collagen by fibroblasts, angiogenesis,

\footnotetext{
${ }^{*}$ Corresponding author: Priyani Peiris

Department of Shalya - Shalakya, Faculty of Indigenous Medicine, Gampaha Wickramarachchi University of Indigenous Medicine, Sri Lanka.

Copyright (C) 2021 Author(s) retain the copyright of this article. This article is published under the terms of the Creative Commons Attribution Liscense 4.0.
} 
contraction of wound area and scar remodeling [2]. An acute wound may continue to a chronic phase if the treatment fails. In chronic wounds the repair process is disrupted due to inflammation or infection. Staphylococcus aureus, Streptococcus pyogenes, Enterococci and Pseudomonas aeruginosa are common bacterial strains that are responsible for the formation of purulent exudate in chronic wounds [3]. Personnel habit of purchasing antibiotics over the counter as a cure for wounds has created a complex clinical scenario of antibiotic resistance. Oxidant damage to the regenerating tissue may also delay the wound healing process [4]. Promotion of antioxidant defense proteins (hemi oxygenase -I and keratinocyte growth factor) have shown a positive role on wound healing by regenerating tissue against oxidant damage [4] Collagen is the major extracellular matrix component that supports the healing wounds and some pharmacological agents enhance collagen synthesis aiding wound healing [2].

Currently there are diverse treatment options available in the allopathic medicinal system for chronic wounds and most of them are ineffective, complicated and costly [5]. Systemic glucocorticoids used as an anti-inflammatory agent are proven inhibitors of wound healing via suppression of fibroblast proliferation, collagen synthesis, promoting degradation of collagen and reduced angiogenesis [6,7]. Further these substances may increase the risk of wound infection [8].

Among different treatment options, medicinal plants are frequently used for various illnesses in Sri Lanka and approximately $60-70 \%$ of the rural population still relies on an indigenous medicinal system for their main source of primary health care [9]. Before Ayurveda and modern medicine rooted in Sri Lanka there was a unique system of medicine called indigenous medicine which used substances derived from animals, plants and minerals to treat the man.

Considering wounds, there are separate indigenous generations of physicians for abscess, wound and cancer (GediVana-Pilika traditions) as they are the expertise in treating those conditions. Indigenous written evidence of managing wounds form the basis of crude remedies needed to staunch bleeding, reduce swelling, minimize pain, remove damage tissue, treat infections, mask foul smells and promote healing. These wound healing measures are well described in the texts. These are time tested, well proven and effective remedies being in use since thousands of years. But in the current practice, these measures remain somewhat hidden behind the concepts of modernization. Therefore, it is necessary to explore these hidden treasures in order to preserve the valuable information for future generations.

Hence, this scholarly study aimed at providing a scientific background from contemporary evidence to justify the use of herbs mentioned in the treatment of wounds by traditional healers of Sri Lanka. Further the study is aimed at acknowledging the valuable spiritual knowledge that was originated long years back which now have been proven with evidence based on modern literature.

\section{Methodology}

Wound healing remedies were studied referring 22 Indigenous books of Thalpathe piliyam, (published by the Department of Ayurveda, Sri Lanka) which is the written evidences of ancient Ola leaf manuscripts. These Ola leaf manuscripts are thousands of years' age old and the spiritual knowledge on disease cure which is native to Sri Lankan traditional healers are documented and preserved for the generations to come in this unique field.

The data on wound healing were gathered separately based on different herbal applications used for the treatment of wounds (Table 1). The gathered data were systematically analysed to reveal most frequently used herbs in those different topical applications. Among those common herbs seven (07) were selected for this review as they were the most frequently mentioned in the remedies (Table 2). A bibliographic investigation was accomplished by analysing worldwide scientific databases (PubMed, Scopus and Google Scholar) for the available information on the mechanism/s or pharmacological activities of selected medicinal plants related to wound healing. Thus, each herb was searched along the key words "wound healing", "antimicrobial", "antioxidant or radical scavenging" and "anti-inflammatory". Further each plant was searched on their "wound healing" activity for other mechanisms and modes which was not directly included in the list of key words.

\section{Results and discussion}

\subsection{Different types of external applications and their frequency of usage}

According to the comprehensive study on twenty-two Ola leaf records, there are many dosage forms of external applications found in treating wounds. This study reported majority of recipes are oils (37\%), swarasa (fresh juices) 
(25\%) and mallum (salad) (20\%). In addition to that, bolus fermentation, Dhoopana (fumigation) and churna (powder) reported percentages of $8 \%$ and $5 \%$ each from last two preparations respectively.

\subsubsection{Commonly indicated plants for wound healing}

Table 1 Frequently used plants for topical application of wound management filtered from 22 Ola leaf manuscripts from Indigenous Medical System of Sri Lanka

\begin{tabular}{|l|l|l|l|}
\hline Scientific name & Family & Vernacular name & $\begin{array}{l}\text { Part/s mentioned in ola leaves for } \\
\text { wound healing }\end{array}$ \\
\hline Pongamia pinnata & Fabaceae & Magul karada & root bark, bark, leaves and seeds \\
\hline Curcuma longa & Zingiberaceae & Kaha & Rhizomes \\
\hline Jasminum sambac & Oleaceae & Geta pichcha & Whole plant \\
\hline Azadirachta indica & Meliaceae & Kohomba & Bark, leaves, seeds \\
\hline Glycyrrhiza glabra & Leguminosae/Fabaceae & Walmee & Whole plant \\
\hline $\begin{array}{l}\text { Desmodium } \\
\text { triflorum }\end{array}$ & Fabacea & Heen undupiyaliya & Whole plant \\
\hline $\begin{array}{l}\text { Vernonia zeylanica } \\
\text { Asteraceae }\end{array}$ & $\begin{array}{l}\text { Pupula/Heen } \\
\text { bovitiya }\end{array}$ & Whole plant \\
\hline
\end{tabular}

\subsection{Evidences from modern literature to scaffold the usage of selected plants for wound healing in traditional practice}

In the following section, the authors wish to provide evidences to bridge the gap in scientific knowledge for the traditional use of selected herbs in wound healing remedies mentioned in Ola leaves native to Sri Lanka. Scientific evidences gathered are presented under mechanisms related to wound healing activity such as antimicrobial, antiinflammatory, antioxidant and reported as wound healing per se by other mechanisms.

\subsubsection{Pongamia pinnata}

Traditionally different parts of the plant such as leaves, bark, root bark and seeds are included in the wound healing remedies in the indigenous medical system of Sri Lanka. Studies have shown that different parts of the plant are effective in inhibiting the growth of S. aureus and P. aeruginosa that are found in infected wounds. Chloroform, ethyl acetate and methanol fractions of leaves were effective against $S$. aureus and P. aeruginosa $[10,11]$. Further, studies have shown that silver nano particles synthesised by using dried leaves effectively hinder the growth of $S$. aureus and $P$. aeruginosa [12] . Apart from the leaves, methanolic and ethanolic extracts of seeds also have inhibited the growth of S. aureus and $P$. aeruginosa $[11,13]$. The flavonoid derivatives; karangin and Pongal have been isolated as antimicrobial substances present in P. pinnata and also reported its' inhibitory activity on DNA and RNA synthesis in S. aureus $[10,11,13]$.

The anti-inflammatory effect of $P$. pinnata was studied in three different stages (acute, sub-acute and chronic) by using different animal models. Extracts of leaves, stem bark and seed were found to be effective in resolving the acute inflammation in test animal models $[14,15,16,17]$. The study conducted by Dwivedi et al., (2017) has revealed that pro inflammatory cytokines, TNF- $\alpha$ levels were reduced and it can be claimed that inflammatory markers may have a role in angiogenesis of wounds [18]. Studies have shown that stem bark and leaves have the ability to resolve oedema in chronic inflammation $[17,19]$. Badole et al., $(2010)$ have revealed that the stem bark had the ability to reduce inflammatory markers, TNF- $\alpha$ and IL-1 $\beta$ in acute and chronic inflammatory models [20]. Thus, P. pinnata may have the potential in resolving the inflammation in the vicinity of the wound area.

Methanol extract of bark, leaves and stem has shown to be effective in scavenging DPPH radicals and has demonstrated enhanced $\mathrm{Fe}^{3+}$ reducing capacity [21]. Furthermore, methanol leaf extract had the potential to inhibit lipid peroxidation and to reduce glutathione levels [22] Reduction in glutathione levels and elevation of anti-oxidant enzymes such as superoxide dismutase and catalase levels were observed in rat models treated with methanolic leaf extract [18]. Increased levels of antioxidant enzymes lead to scavenging of superoxide radicals and protect viable tissues in the wounds [18]. 
Excision and incision wound models were used to evaluate the wound healing capacity of P. pinnata. Methanol and ethanolic leaf extracts had increased wound healing capacity by reducing wound size in test animals when compared with control [22,23]. Furthermore, wound healing potential was enhanced through increasing wound contraction capacity, tensile strength, hydroxy proline and hexosamine contents [18]. Further, the bark of P.pinnata. has shown analgesic properties as evident from acetic acid induced abdominal writhing and hot plate test in mice [20]. Attenuation of pain by P. pinnata would be another reason for inclusion in wound healing remedies as evident in Ola leaf manuscripts.

\subsubsection{Curcuma longa}

C. longa is a unique medicinal plant in indigenous remedies and proven to be effective in resolving wounds as evident by its antimicrobial, antioxidant and anti-inflammatory properties. The active principle in Curcuma is a group of phenolic compounds including curcuminoids and have been reported to possess diverse biologic activities [24, 25]. Aqueous extract $C$. longa has shown the inhibition of growth of $S$. aureus [26]. Methanolic extract exhibited retardation of the growth in $S$. aureus and P. aeruginosa [27]. These studies justify the potential use of $C$. longa in suppurated wounds with purulent discharges.

Effect of aqueous extract of $C$. longa on interleukins and prostaglandins of mouse splenocytes and macrophages were evaluated in an in vitro study [24]. It was evident that both the IL-12 and PGE 2 levels were significantly reduced in the cell lines treated with Curcuma. Scientific evidences claim that curcumin has the ability to inhibit cyclooxygenase enzymes are responsible for the formation of inflammatory mediators [25]. Inhibition of leukotriene B4 formation in rat polymorph nuclear neutrophils also have been demonstrated the potent anti-inflammatory activity of $C$. longa [28].

The effect of topical curcumin was studied in wounds of rat models and histopathological evaluation confirmed a marked reduction in cellular hyperplasia, leucocyte infiltration and oedema [29]. Apparently reduced inflammatory response may responsible for enhanced wound healing potential.

Essential oil and ethanol oleoresin extracted from fresh rhizomes of $C$. longa has shown to be effective in reducing lipid peroxidation in vitro [30]. Further these compounds had enhanced capacities in DPPH radical scavenging, oxygen radical absorbance and metal iron chelating activities showing its' marked antioxidant activity [30,31]. Curcumin I, II and III isolated from rhizomes have shown to be responsible for the potent antioxidant capacity of curcuma [25].

Ethanolic extract of $C$. Longa in the form of topical ointment had been applied in excision wounds of rats and reported faster healing effect through histopathogical evaluation when compared with control animals [32,33]. Immunohistochemical localisation studies showed an increased in transforming growth factor - $\beta 1$ m-RNA expression and delay in the cellular apoptosis in rats with diabetic wounds which may contribute towards enhanced wound healing [34]. Oral and topical application of curcumin in rats showed early re-epithelialization, improved neovascularization, increased migration of fibroblasts and macrophages into wound bed and higher collagen content, further supporting the wound healing capacity of active compounds of Curcuma [34]. Skin wounds of rabbits were treated successfully by applying curcumin powder [35]. Moreover, it has been documented that curcumin stimulates the production of growth factors involved in wound healing process further enhances the healing process [36].

\subsubsection{Jasminum sambac}

J. sambac is an ethno medicinally important plant and a key ingredient in wound healing remedies stated in indigenous medicine. In modern literature it has been claimed that the plant has bacteriostatic effect against predominant bacteria responsible in chronic wounds. Water extract and the crude methanolic extract of J. sambac has shown to be effective against $S$. aureus $[37,38]$. Ethanolic extract of leaves had inhibition on the growth of P. aeruginosa [39].

Crude leaf extract and ethanolic root extracts of $J$. sambac had shown to resolve edema in acute inflammatory rat models $[40,41]$. Ethanolic root extract was also effective in inhibiting sub chronic and chronic inflammatory responses [41]. This study evident that hesperidin, a chemical compound isolated from the ethanolic extract of the Jasminum flower has anti-inflammatory activity and may have contributed to increased wound healing capacity [41].

Sengar et al., (2015) has investigated the radical scavenging activity of the ethanolic root extract on oedematous tissu es of rats exposed to acute inflammatory models and reported there was a marked reduction in lipid peroxidation [41]. Further, the study reported that the levels of superoxide dismutase and catalase was also less in the blood of test animals indicating reduce oxidation stress. The protection towards oxidants may be useful in protecting the wound healing tissues. 
Methanolic flower extract and hydroalcoholic leaf extracts were effective in free radical scavenging as shown by assays of DPPH, hydroxy radical, hydrogen peroxide, superoxide anion and nitric oxide radical scavenging assays [42,43]. Phytochemicals such as alkaloids, glycosides, tannins and flavonoids have been quantified from leaves of Jasmin and these chemical entities possesses free radical scavenging activity [43].

Investigations carried out by Anima et al., (2019) have demonstrated that ethanolic extract of flowers show possible curative effect on excision and incision wound models of rats [39]. A higher rate of wound contraction, increased collagen content and favourable histopathological changes were evident in treated groups when compared with controls. Aqueous and ethanol extracts of leaves in a form of ointment was applied in excision wound models in mice and showed a significant and rapid wound healing process [44]. In this study, the effect of gelatine blended flower extract incorporated film was evaluated on viability of fibroblast cells and enhanced viability was observed.

Ethanolic flower extract has shown a significant analgesic activity in albino rats as demonstrated by reduced writhing count and increased latency in flicking test [41]. This may potentiate the reduction in pain associated with wounds and could justify the inclusion of Jasminum in wound healing remedies in Sri Lankan traditional medicine.

\subsubsection{Azadirachta indica}

A. indica (Neem) contains valuable active compounds such as azadirachtin, nimbolinin, nimbin, nimbidin, nimbidol, salannin and quercetin and its versatile therapeutic effect is attributed to these active compounds [46]. Leaf and bark extract of $A$. indica have shown the inhibition of growth of $S$. aureus $[47,48]$. Neem shows its anti-microbial activity through cell wall breakdown [46].

A. indica has proven to be effective in resolving inflammatory response and possibly would have shown beneficial effects in including wound healing remedies. Water soluble part of alcoholic extract of leaves has demonstrated effect in chronic inflammation through rat models [49]. Seed oil was effective in reducing the acute inflammatory response as evident by carrageenan-induced hind paw oedema of albino rats [50]. Carbon tetrachloride extract of fruit skin and its isolated constituent, azadiradione were effective in resolving acute inflammation [51]. An important study has revealed that nimbidin present in leaves supresses the functions of macrophages and neutrophils which mediate the inflammatory response [52].

Several studies have shown that $A$. indica is a medicinal plant with potent antioxidant capacity. Aqueous, methanolic and ethanolic extract of root and bark had demonstrated significant DPPH radical scavenging activity in in vitro studies $[53,54]$. Radical scavenging activity of leaves, fruits, flowers and stem bark extracts had been evaluated by DPPH radical scavenging activity assay, total antioxidant activity assay and inhibition of lipid peroxidation in a cancer cell culture by the thiobarbituric acid reactive substances (TBARS) method [55]. The results suggested that the plant possesses higher free radical scavenging, greater antioxidant activity and reduced lipid peroxidation effects [55]. Neem is a rich source of antioxidant and thus shows free radical scavenging properties. Azadirachtin and nimbolide have shown concentration dependent antiradical scavenging activity in the order of nimbolide $>$ azadirachtin $>$ ascorbate [56].

Azadiradione, a biologically active compound from A. indica has reported to exhibit significant anti-nociceptive and antiinflammatory activities on animal models and the study had rationalised the ethno medicinal use of the plant for wound, burns and injuries by Tribal people. [51]

Topical application of $A$. indica was shown to be effective in curing incision and excision wounds in animal models. Ethanolic extracts of stem bark and leaves have been proved its' fast wound healing effect on incision and excision wounds of rats with increased tensile strength, increased anti-inflammatory response and neovascularization [57,58, $59,60]$. The wounds treated with the plant extract had shown enhanced wound contraction, increased amounts of hydroxyproline, DNA and protein content and lead to rapid wound healing [61].

\subsubsection{Glycyrrhiza glabra}

G. glabra is one of the oldest and widely used herb from ancient medical history of indigenous system both as a medicine and also as a flavouring to disguise the unpleasant flavour of other medications. Many of the claims for the effectiveness of G.glabra extracts have been shown by modern science to be credible, a root compound (Glycyrrhizin) being generally regarded as the major biologically active compound [62]. Studies have shown that G.glabra is effective in inhibiting growth of wound causing bacteria. Ethanolic and aqueous extracts of root and leaves has supressed the colonies of S.aureus and P. aeruginosa effectively $[63,64]$. Ether, chloroform and acetone extracts of root was shown to be effective in inhibiting the growth of S. Aureus and P. aeruginosa [62]. 
The chemical compounds responsible for the anti-inflammatory effect of G. glabra have been isolated as licoflavanone [65]. This compound had been extracted from leaves and has shown to reduce nitrile levels, pro-inflammatory cytokines and cyclooxygenase 2 expression levels in lipopolysaccharide stimulated murine macrophages. Perhaps, these mechanisms play a role in wound healing clamming its' traditional use in different preparations mentioned in Ola leaves.

Chemical compounds, pinocembrin, glabranin and licoflavanone extracted from leaves have shown marked antioxidant activity as shown by DPPH radical scavenging assay and ABTS assay [65]. Isolated flavonoids from G. glabra has shown reduced lipid peroxidation and active oxygen radical levels in in vitro experiments [66]. Hep G2 cells treated with methanol extract of root has shown lower MDA and higher glutathione and catalase levels (as compared to $\mathrm{H}_{2} \mathrm{O}_{2}$ treated Hep G2 cells which showed increased MDA production, decreased glutathione reductase and catalase production [67].

Wound healing capacity of the root extract of G. glabra was evaluated on dermal wounds of rats [68]. Increased number of fibroblasts, capillary buds, collagen content, tensile strength, and reduced surface area of the wound was observed in animals treated with G. glabra.

\subsubsection{Desmodium triflorum}

Few studies were found to support the mechanisms responsible for wound healing by D. triflorum. Aqueous and methanolic extracts of the plant has shown inhibitory effect against S.aureus and P.aeruginosa [69]. Hexane and methanolic extract have demonstrated to be effective in resolving paw oedema in acute inflammation of carrageenaninduced mice models [70,71]. Anti-oxidant capacity of the ethyl acetate fraction of the plant was evaluated by DPPH radical scavenging assay and Trolox equivalent antioxidant capacity assay [72]. Both assays revealed that the plant extract was effective in reducing the oxidant stress [72].

D. triflorum has shown to be a potent analgesic and thus possibility exists to be included in the wound healing remedies $[70,71]$. Cold water extract of plant has shown to possess antinociceptive activity and the action is mediated by supraspinal mechanisms, possibly via alkaloid and flavonoids [73]. Therefore D. triflorum may have pain killing activity and the traditional use probably presume to reduce pain in the wounds [73].

\subsubsection{Vernonia zeylanica}

This is an endemic plant to Sri Lanka and therefore scanty literature was found supporting its' use to alleviate wound complications via exhibiting it's anti-inflammatory activity and antinociceptive potential [74,75]. Methanol/dichloromethane extract of plant has shown to inhibit the production of nitric oxide and superoxide in invitro experiments demonstrating its anti-inflammatory activity [74].

The antinociceptive action was found to be mediated centrally at the supraspinal level via opioid receptor mechanisms and effective against neurogenic and inflammatory pain explaining its' wider use in traditional medicine in Sri Lanka mainly for bone fractures other than wound healing [75].

Among the different preparations insisted for wound healing P. pinnata (40 remedies), V. zeylanica (20 remedies), curcuma longa (25 remedies), A. indica (15 remedies), G. glabra (10 remedies), J. sambac (08 remedies) are the herbals found mostly in Ola leaf prescriptions.

P. pinnata was mostly found in oil preparations. $V$. zeylanica was recorded in remedies used to produce bolus fermentation and fresh preparations. C.longa was widely included in mellum preparations and oils. A. indica was found in oils and fumigation preparations.

\subsection{Evidences from traditional literature to support the claims from Ola leaf manuscripts}

Considering the role of medicinal plants in wound healing process, medicinal plants are more potent healers since they promote the repair mechanisms in the natural way. Therefore, this study has scientifically proven that P.pinnata, $C$. longa, J. sambac, A. indica, G. glabra, D. triflorum, and V. zeylanica act on three phases of wound healing mechanism that are mentioned in literature owing to their specific properties.

Due to their Vrana shothahara (anti - inflammatory) and Raktasthambhana (haemostatic) action on inflammatory phase they promote wound healing [76, 77]. On the other hand, they act on fibroblast proliferation phase since they have krimighna (anti- microbial), Raktashodhaka (blood clarifying) and Vrana shodhaka (wound contraction with increased capillary formation) properties [76, 77]. In remodeling phase their Vrana ropana (promote healing) and Rasayana (free radical scavenging activity) properties enhance and complete the wound healing process [77]. 


\subsection{Chemical compounds related to wound healing activity in selected plants}

Some of the plants recommended in Ola leaves have been studied up to the molecular level and the target compounds with wound healing properties have been isolated and purified. These compounds possess biological activities related to wound healing mechanisms described in the text. Bacteriostatic activity of P.pinnata is due to flavonoid derivatives, karangin and pongal that are present in the bark and leaves [10, 14]. Curcumin I, II and III are potent biological compounds extracted from rhizomes of Curcuma and have shown antioxidant and anti-inflammatory activities [24, 25]. Hesperidin is the major bioactive compound found in Jasmine flowers and it mediates the anti-inflammatory activity [41]. Anti-inflammatory activity of $A$. indica is owing to azadiradione while azadirachtin and nimbolide is responsible for the antioxidant activity $[51,56]$. Antimicrobial and anti-inflammatory properties are due to licoflavanone and glycyrrhizin, the isolated chemical compounds present in G.glabra [66, 67]

\section{Conclusion}

Current literature provides strong justification for the wound healing potential of selected plants and therefore, provides the scientific rationale for including them in various remedies mentioned in Sri Lankan traditional medical system. Among the seven medicinal plants identified as evident from Ola leaves, five plants have proven the activities in all searched mechanisms of wound healing revealing anti-bacterial, anti-inflammatory and antioxidant. Presence of antioxidant and anti-inflammatory effects in D. triflorum was also evident.

However, the least studied was V. zeylanica which is an endemic plant to Sri Lanka. This plant has proven antinociceptive efficacy and that it may be prescribing as an herbal pain alleviating agent for wounds among traditional healers [75]. Aqueous extract of $D$. triflorum is also used in indigenous medicine as a pain relieving remedy. Therefore, it is presumed that $V$. zeylanica and D. triflorum had been used to relive pain associated with wounds. P. pinnata, Jasminum and A. indica too, possess pain relieving property as supported by modern literature and might have used in wound healing remedies to attenuate pain. The active compounds isolated and purified may serve as lead for the development of new drugs for wound healing upon completing clinical trials.

Hence, many of the early claims for the effectiveness of authentic plant-based remedies for wound healing used by traditional healers have been shown by modern science to be credible. Undoubtedly, the spiritual folkloric knowledge which the traditional healers had, to be accredited for initiating the most effective treatments in a deserted era of evidences.

\section{Compliance with ethical standards}

\section{Disclosure of conflict of interest}

The authors declare that there is no conflict of interests regarding the publication of this paper.

\section{References}

[1] Hosseinkhani A, Falahatzadeh M, Raoofi E, Zarshenas MM. An evidence-based review on wound healing remedies from reports on Traditional Persian Medicine. Journal of Evidence Based Complementary and Alternative Medicine. 2017; 22(2): 334-343.

[2] Mohan H. Text Book of Pathology $7^{\text {th }}$ Edition.

[3] Brookes G, Carroll KC, Butel G, Morse S. Medical Microbiology. 24 ${ }^{\text {th }}$ Edition.

[4] Sen CK, Khanna S, Gordillo G, Bagchi D, Bagchi M, Roy S.Oxygen, oxidants and antioxidants in wound healing. Annals of New York Academy of Science. 2002; 957: 239-249.

[5] Su S, Hua Y, Wang Y, Gu W, Zhou W, Duan JA, Jiang H, Chen T, Tang Y. Evaluation of anti-inflammatory and analgesic properties of individual and combined extracts from Commiphora myrrha and Boswellia carterii. Journal of Ethnopharmacology. 2012; 139: 649-656.

[6] Anstead GM. Steroids, retinoids, and wound healing. Advances in wound care: the journal for prevention and healing. 1998; 11(6): 277-285.

[7] Brauchle M, Fässler R, Werner S. Suppression of keratinocyte growth factor expression by glucocorticoids in vitro and during wound healing. Journal of Investigative Dermatology. 1995; 105(4): 579-584. 
[8] Wang AS, Armstrong EJ, Armstrong AW. Corticosteroids and wound healing: clinical considerations in the perioperative period. American Journal of Surgery. 2013; 206(3): 410.

[9] Sathasivampillai SV, Rajamanoharan PR, Munday M, Heinrich M. Plants used to treat diabetes in Sri Lankan Siddha Medicine-An ethnopharmacological review of historical and modern sources. Journal of Ethnopharmacology. 2017; 198: 531-599.

[10] Panigrahi S, Mahapatra S. Evaluation of Antibacterial Activity of Pongamia pinnata L., Curcuma longa L. and Mentha arvenis L. a gainst Staphylococcus aureus. International Journal of ChemTech Research. 2016; 9(2): 205212 .

[11] Bajpai VK, Rahman A, Shukla S, Mehta A, Shukla S, Arafat SMY, Rahman M, Ferdousi Z. Antibacterial activity of leaf extracts of Pongamia pinnata from India. Pharmaceutical Biology. 2009; 47(12): 1162-1167.

[12] Raut RW, Kolekar NS, Lakkakula JR, Mendhulkar VD, Kashid SB. Extracellular synthesis of silver nanoparticles using dried leaves of Pongamia pinnata (L) pierre. Nano Micro Letters. 2010; 2(2): 106-113.

[13] Rani MS, Dayanand CD, Shetty J, Vegi PK, Kutty AVM. Evaluation of Antibacterial Activity of Pongamia pinnata linn on Pathogens of Clinical Isolates. American Journal of Phytomedicine and Clinical Therapeutics. 2013; 1(8): 645-651.

[14] Sagar R, Dumka VK, Rajdeep K, Singla S. Evaluation of anti-inflammatory, antibacterial and acaricidal activities of various leaf extracts of Pongamia pinnata. Journal of Pharmacognosy and Phytochemistry. 2018; 7(1): 24642467.

[15] Sagar MK, Upadhyaya K. In vitro Anti-Oxidant, Anti-Nociceptive and Anti-inflammatory properties of Panama pinnata stem bark in experimental animal models. International Journal of Herbal Medicine. 2013; 1(2): 35-43.

[16] Singh RK, Pandey BL. Anti-inflammatory activity of seed extract of Pongamia pinnata in rat. Indian Journal Physiology and Pharmacology. 1996; 40(4): 355-358.

[17] Srinivasan K, Muruganandan S, Lal J, Chandra S, Tandan SK, Prakash VR. Evaluation of anti-inflammatory activity of Pongamia pinnata leaves in rats. Journal of Ethnopharmacology. 2002; 78: 151-157.

[18] Dwivedi D, Dwivedi M, Malviya S, Singh V. Evaluation of wound healing, anti-microbial and anti-oxidant potential of Pongamia pinnata in wistar rats. Journal of Traditional and Complementary Medicine. 2017; 7: 79-85.

[19] Smitha GN, Asif AK, Mukesh SS, Geetanjali SS. Anti-inflammatory activity of Pongamia pinnata stem bark in rats. Journal of Pharmacy Research. 2010; 3(4): 828-830.

[20] Badaole SL, Zanwar AA, Ghule AE, Ghosh P, Bodhankar SL. Analgesic and anti- inflammatory activity of alcoholic extract of stem bark of Pongamia pinnata (L) Pierre.Biomedicine and Ageing Pathology. 2012. 2(1): 19-23.

[21] Sajid ZI, Anwar F, Shabir G, Rasul G, Alkharfy KM, Gilani AH. Antioxidant, antimicrobial properties and phenolics of different solvent extracts from bark, leaves and seeds of Pongamia pinnata (L.) Pierre. Molecules. 2012; 17: 3917-3932.

[22] Prasad MS, Venkateshwarlu G, Dhanalakshmi CH, Kumar DS, Alekhya K, kumar BP, Rajkumar JV. Wound Healing Activity of Pongamia Pinnata in Albino Wistar Rats. Research Journal of Pharmaceutical, Biological and Chemical Sciences. 2011; 2(3): 1096-1100.

[23] Bhandirge SK, Tripathi AS, Bhandirge RK, Chinchmalatpure TP, Desai HG, Chandewar AV. Evaluation of wound healing activity of ethanolic extract of Pongamia pinnata bark. Drug Research. 2015. 65(6): 296-299.

[24] Chandrasekaran CV, Sundarajan K, Edwin JR, Gururaja GM, Mundkinajeddu D, Agarwal A. Immune-stimulatory and anti-inflammatory activities of Curcuma longa extract and its polysaccharide fraction. Pharmacognosy Research. 2013; 5(2): 71-79.

[25] Ramsewak RS, De Witt DL, Nair MG. Cytotoxicity, antioxidant and anti-inflammatory activities of Curcumins I-III from Curcuma longa. Phytomedicine. 2000; 7(4): 303-308.

[26] Niamsa N, Sittiwet C. Antimicrobial activity of Curcuma longa aqueous extract. Journal of Pharmacology and Toxicology. 2009; 4(4): 173-177.

[27] Raji EFPA, Ibrahim, Tarek N. Antibacterial activity of Curcuma longa, Opuntia ficus-indica and Linum usitatissimum. MOJ Toxicology. 2018; 4(3): 214-220.

[28] Amon HP, Anazodo MI, Safayhi H, Dhawan BN, Srimal RC. Curcumin: A potent inhibitor of leukotriene B4 formation in rat peritoneal polymorphonuclear neutrophils (PMNL). Planta Medica. 1992; 58: 226. 
[29] Emiroglu G, Coskun ZO, Kalkan Y, Erdivanli OC, Tumkaya L, Terzi S,1 Özgür A, Demirci M, Dursun E. The Effects of Curcumin on Wound Healing in a Rat Model of Nasal Mucosal Trauma. Evidence-Based Complementary and Alternative Medicine. 2017.

[30] Singh G, Kapoor IPS, Singh P, de Heluani CS, Marina P de Lampasona MP, Catalan CAN. Comparative study of chemical composition and antioxidant activity of fresh a dry rhizomes of turmeric (Curcuma longa Linn.). Food and Chemical Toxicology. 2010; 48: 1026-1031.

[31] Akter J, Hossain MA, Takara K, Islam MZ, Hou DX. Antioxidant activity of different species and varieties of turmeric (Curcuma sp): Isolation of active compounds. Comparative Biochemistry and Physiology Part C: Toxicology \& Pharmacology. 2019; 215(9): 17-30.

[32] Purohit SK, Solanki R, Mathur V, Mathur M. Evaluation of Wound Healing Activity of Ethanolic Extract of Curcuma longa Rhizomes in Male Albino Rats. Asian Journal of Pharmaceutical Research. 2013; 3(2).

[33] Pawar RS, Toppo FA, Mandloi AS, Shaikh S. Exploring the role of curcumin containing ethanolic extract obtained from Curcuma longa (rhizomes) against retardation of wound healing process by aspirin. Indian Journal of Pharmacology. 2015; 47(2): 160-6.

[34] Sidhu GS, Mani H, Gaddipati JP, Singh AK, Seth P, Banaudha KK, Patnaik GK, Maheshwari RK. Curcumin enhances wound healing in streptozotocin induced diabetic rats and genetically diabetic mice. Wound Repair Regeneration. 1999; 7(5): 362-374.

[35] Gayathri A, Sekar DS, Sakthi R. Wound Healing Activity of Curcuma longa with Oleum olivae. Journal of Academia and Industrial Research. 2015; 3(10): 479-480.

[36] Tejada S, Manayi A, Daglia M, Nabavi SF, Sureda A, Hajheydari Z, Gortzi O, Pazoki-Toroudi H, Nabavi SM. Wound healing effects of curcumin. Current Pharmaceutical Biotechnology. 2016; 17(11): 1002-1007.

[37] Navneet SK, Gautam SS. Screening of Antimicrobial Properties of Jasminum sambac linn. Leaf Extracts against Dental Pathogens. Research Journal of Phytochemistry. 2015; 9: 195-200.

[38] Koly SF. In vitro antibacterial activity of crude methanolic extracts from leaves of Jasminum sambac. Indo American Journal of Pharmaceutical Science. 2016; 3(6): 560-565.

[39] Anima P, Arun M, Satish S. Scientific validation of wound healing potential of Jasminum sambac Ait. South African Journal of Botany. 2019; 121: 584-589.

[40] Belango YMC, Cruz AF, Miguel RB, Rotairo CRL, Oli RT. Anti-inflammatory Property of the Formulated Topical Gel from the Crude Leaf Extracts of Sampaguita (Jasminum sambac L. Family: Oleaceae). International Journal of Chemical Engineering and Applications. 2016; 7(3): 199-204.

[41] Sengar N, Joshi A, Prasad SK, Hemalatha S. Anti-inflammatory, analgesic and anti-pyretic activities of standardized root extract of Jasminum sambac. Journal of Ethnopharmacology. 2015. 3; 160: 140-8.

[42] Kalaiselvi M, Narmatha R, Ragavendran P, Ravikumar G, Sophia D, Gomathi D, Arulraj C, Kumar D, Guru Uma C, Kalaivani K. In vitro free radical scavenging activity of Jasmine sambac (L.) Ait oleaceae flower. Asian Journal of Pharmaceutical and Biological Research. 2011; 1(3): 370-375.

[43] Krishnaveni A, Thakur SR. Free radical scavenging activity of Jasminum sambac. Journal of Global Trends in Pharmaceutical Sciences. 2014; 5(2): 1658-1661.

[44] Sabharwal S, Aggarawal S, Vats M, Sardana S. Preliminary phytochemical investigation and wound healing activity of Jasminum sambac (linn.) ait. (Oleaceae) leaves. International Journal of Pharmacognosy and Phytochemical Research. 2012; 4(3): 146-150.

[45] Eakwaropas P, Wisidsri N. Effect of Jasminum sambac Flower Extracts on Fibroblast Cell Viability and Film Characteristics. Applied Mechanics and Materials. 2019; 886: 27-33.

[46] Alzohairy MA. Therapeutic role of Azadirachta indica (Neem) and their active constituents in disease prevention and treatment. Evidence-Based Complementary and Alternative Medicine. 2016.

[47] Challa K. Antimicrobial activity of Azadirachta Indica (neem) leaf, bark and seed extra International Journal of Research in Phytochemistry and Pharmacology. 2013; 3(1): 1-4.

[48] Margathavalli S, Brindha S, Kaviyarasi S, Gangwar SH, Annadurai B. Antimicrobial Activity in leaf extract of neem. International Journal of Science and Nature. 2012; 3(1): 110-113. 
[49] Chattopadhyay RR. Possible biochemical mode of anti-inflammatory action of (Azadirachta Indica) A. Juss. In rats. Indian Journal of Experimental Biology. 1998; 36(4): 418-420.

[50] Naik MR, Bhattacharya A, Behera R, Agrawal D, Dehury S, Kumar S. Study of anti- inflammatory effect of neem seed oil (Azadirachta Indica) on infected albino rats. Journal of Health Research and Reviews. 2014; 1(3): 66-69.

[51] Ilango K, Maharajan G, Narasimhan S. Anti-nociceptive and anti-inflammatory activities of (Azadirachta Indica) fruit skin extract and its isolated constituent azadiradione. Natural Product Research. 2013; 27(16): 1463-1467.

[52] Kaur G, Alam MS, Athar M. Nimbidin supresses functions of macrophages and neutrophils: relevant to its antiinflammatory mechanisms. Phytotherapy Research. 2004; 18(5): 419-424.

[53] Nahak G, Sahu RK. Antioxidant activity of Neem (Azadirachta Indica) and Mahaneem (Melina azedarach). Continental Journal of Pharmaceutical Sciences. 2010; 428-34.

[54] Kiranmail M, Kumar MCB, Ibrahim MD. Free radical scavenging activity of neem tree (Azadirachta indica A. juss var., meliaceae) root bark extract Asian J Pharm Clin Res. 2011; 4(4): 134-136.

[55] Sithisarn P1, Supabphol R, Gritsanapan W. Antioxidant activity of Siamese neem tree. Journal of Ethnopharmacology. 2005; 99(1): 109-12.

[56] Hossain MA, Al-Toubi AS, Weli MA, Al-Riyami QA, Ai-Sabahi JN. Identification and characterization of chemical compounds in different crude extracts from leaves of Omani neem. Journal of Taibah University for Science. 2013; 7(4): 181-188.

[57] Babu KS, Krishna V, Naik VKM, Latha J, Prabhakar V. Wound healing activity of ethanolic extract of natural products (Azadirachta Indica bark) in Albino Wistar rats. World Journal of Pharmacy and Pharmaceutical Sciences. 2016; 5(6): 1624-1632.

[58] Nagesh HN, Basavanna PL, Kishore MS. Evaluation of wound healing activity of ethanolic extract of Azadirachta Indica leaves on incision and excision wound models in Wistar albino rats. International Journal of Basic and Clinical Pharmacology. 2015; 4(6).

[59] Maan P, Yadav KS, Yadav NP. Wound Healing activity of Azadirachta indica A. Juss stem bark in mice. Pharmacognosy Magazine. 2017; 13(2): S 316-320.

[60] Barua CC, Talukdar A Barua AG, Chakraborty AG, Sarma RK, Bora RS. Evaluation of wound healing activity of methanolic extract of Azadirachta indica (Neem) and Tinospora cordifolia (Guuchchi) in rats. Pharmacology online. 2010; $1: 70-77$.

[61] Emeka A0, Olotu Emamoke J. Theodore AA and Julius CO. The wound healing effects of aqueous leave extracts of Azadirachta indica on wistar rats. Journal of Natural Science and Research. 2013; 3(6).

[62] Nitalikar MM, Munde KC, Dhore BV, Shikalgar SN. Studies of Antibacterial Activities of Glycyrrhiza glabra Root Extract. International Journal of Pharm Tech Research. 2(1): 899-901.

[63] Irani M, Sarmadi M, Bernard F, Hossein G, Pour E, Bazarnov HS. Leaves Antimicrobial Activity of Glycyrrhiza glabra L. Iranian Journal of Pharmaceutical Research. 2010; 9(4): 425-428.

[64] Bassoon RH, KamelZ, Megahid A, Samir E. Antimicrobial potential of licorice: Leaves versus roots. African Journal of Microbiology Research. 2012; 6(49): 7485-7493.

[65] Frattaruolo L, Carullo G, Brindisi M, Mazzotta S, Bellissimo L, Rago V, Curcio R, Dolce V, Aiello F, Cappello AR. Antioxidant and Anti-Inflammatory Activities of Flavanones from Glycyrrhiza glabra L. (licorice) Leaf Phytocomplexes: Identification of Licoflavanone as a Modulator of NF-kB/MAPK Pathway.Antioxidants (Basel). 2019; 8(6): 186.

[66] Ju HS, Li XJ, Zhao BL, Han ZW, Xin WJ. Effects of Glycyrrhiza Flavonoids on lipid peroxidation and active oxygen radicals. Acta Pharmaceutica Sinicia. 1989; 24(11): 807-812.

[67] Shinde DB, Koratkar SS. Antioxidant activity and antiproliferative action of methanolic extract of Liquorice (Glycyrrhiza glabra) in Hep G2 cell line. International Journal of Pharmacy and Pharmaceutical Sciences. 2016. $8(9)$.

[68] Oloumi MM, Derakhshanfar A, Nikpoor A. Healing potential of liquorice root extract on dermal wounds in rats. Journal of Veterinary Research. 2007; 62(4): 147-154.

[69] Sharma R, Parashar B, Kabra A. Efficacy of aqueous and methanolic extracts of plant Desmodium triflorum for potential antibacterial activity. International Journal of Pharmaceutical Sciences and Research. 
[70] Lai SC1, Peng WH, Huang SC, Ho YL, Huang TH, Lai ZR, Chang YS. Analgesic and anti-inflammatory activities of methanol extract from Desmodium triflorum DC in mice. American Journal of Chinese Medicine. 2009; 37(3): 57388.

[71] Chowdhury KK, Saha A, Bachar SC, Kundu JK. Analgesic and anti-inflammatory activities of Desmodium triflorum DC. Journal of Biological Sciences. 2005; 5(5): 581-583.

[72] Lai SCI, Ho YL, Huang SC, Huang TH, Wu CR, Liyan Chang YS. Antioxidant and antiproloferative activities of Desmodium triflorum (L.) DC. American Journal of Chinese Medicine. 2010; 38(2): 329-342.

[73] Ratnasooriya WD, Jayakody CA, Ratnasooriya TDC, Weerasekera KR. Antinociceptive activity of cold-water extract of Desmodium triflorum in rats. International Research Journal of Pharmacy. 2011; 2(7): 120-123.

[74] Rukshala BAD. Handunnetti SM, De Silva ED. In vitro anti-inflammatory activity of methanol/dichloromethane extract of Vernonia Zeylanica (L.) Less. Seventh Annual Scientific Sessions of the Institute of Biochemistry, Molecular Biology and Biotechnology, University of Colombo, Colombo, Sri Lanka. 2015.

[75] Ratnasooriya WD, Deraniyagala SA, Peiris SKJS. Antinociceptive Potential of the Sri Lankan Endemic Plant Vernonia zeylanica. Pharmaceutical Biology. 2007; 45(7): 525-532.

[76] Divya Gupta D, Nautiyal U. Ayurvedic remedies for Healing of wounds. International Journal of Pharmaceutical and Medical Research. 2016; 4(4): 342-349.

[77] Ayurveda Pharmacopeia, Volume I, Part II, Published by Department of Ayurveda, $2^{\text {nd }}$ edition. 1994. 